Relato de Experiência

\title{
O Teatro do Oprimido é uma estratégia potente para quê? Uma experiência do Programa de Educação pelo Trabalho para a Saúde no Centro de Atençáo Psicossocial Álcool e outras Drogas
}

\author{
What is the Oppressed Theater a powerful strategy for? An experience of \\ the "Education through Work Program for Health" at the Psychosocial \\ Care Center for Alcohol and other Drugs
}

Adriana Leão ${ }^{\mathrm{a}}$ (D), Suzana Rodrigues Renób (D)

${ }^{a}$ Universidade Federal do Espírito Santos - UFES, Vitória, ES, Brasil.

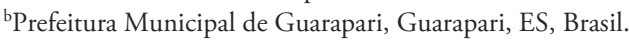

Como citar: Leão, A., \& Renó, S. R. (2021). O Teatro do Oprimido é uma estratégia potente para quê? Uma experiência do Programa de Educação pelo Trabalho para a Saúde no Centro de Atenção Psicossocial Álcool e outras Drogas. Cadernos Brasileiros de Terapia Ocupacional, 29, e2088. https://doi.org/10.1590/2526-8910.ctoRE2088

\begin{abstract}
$\underline{\text { Resumo }}$
Introduçáo: $\mathrm{Na}$ perspectiva de formaçáo para a construção de práticas pertinentes a um modelo de atenção embasado pela lógica psicossocial, que tem como norte a produção de cidadania, autonomia e inclusão social, utilizamos como proposta de intervenção no âmbito do Programa de Educação pelo Trabalho para a Saúde/Redes, junto a um Centro de Atenção Psicossocial Álcool e outras Drogas, as técnicas do Teatro do Oprimido, para promover o protagonismo dos participantes e possibilitar a identificação e o enfrentamento de suas necessidades e das diversas situaçôes de opressão que vivenciaram. Objetivo: Buscamos apresentar o trabalho realizado com as técnicas do Teatro do Oprimido e refletir sobre a sua potencialidade no contexto da Atençáo Psicossocial. Método: Trata-se de um relato de experiência em que foi utilizado o método da narraçáo descritiva para apresentar o processo de realização das oficinas e, posteriormente, as situaçóes e intervençôes ocorridas nas oficinas e processos das mostras. Resultados: A proposta resultou em três mostras do Teatro do Oprimido, "iniciando um caminho contra as opressóes", "desvelando opressóes", e "se correr o bicho pega, se ficar o bicho come!". Conclusóes: A atuação com o Teatro do Oprimido no CAPS-ad se configurou como um trabalho de caráter clínico e político, com atuaçáo sobre a realidade concreta dos protagonistas de suas próprias histórias encenadas. A potencialidade
\end{abstract}


dessa experiência em busca da cidadania contribuiu no sentido de provocar reflexôes e críticas que podem vir a qualificar açóes em prol do paradigma psicossocial no Sistema Único de Saúde (SUS).

Palavras-chave: Saúde Mental, Serviços de Saúde Mental, Opressão Social, Autonomia Pessoal, Participação da Comunidade.

\section{$\underline{\text { Abstract }}$}

Introduction: In the perspective of training for the construction of practices relevant to a model of care based on psychosocial logic, which is guided by the production of citizenship, autonomy, and social inclusion, we used the intervention proposal within the scope of Education through Work for Health Program (PET Saúde/Redes), in a Psychosocial Care Center Alcohol and other Drugs, the techniques of the Teatro do Oprimido [Oppressed Theatre] to promote the protagonism of the participants and make it possible to identify and face their needs and the different oppression situations they experienced. Objective: To present the Oppressed Theater and reflect on its potential in the context of Psychosocial Care. Method: Experience report in which the method of descriptive narration was used to present the process of conducting the workshops, the situations, and interventions that occurred in the workshops and processes of the shows. Results: The proposal resulted in three shows from the Teatro do Oprimido - starting a path against oppression, unveiling oppression, and "if you run, the animal gets you, if you stay, the animal eats you!". Conclusion: The performance with the Teatro do Oprimido in the CAPS-ad was configured as a work of clinical and political character, with performance on the concrete reality of the protagonists of their own staged stories. The potential of this experience in search of citizenship has contributed to provoking reflections and criticisms that may qualify actions in favor of the psychosocial paradigm in the Brazilian Health Unified System (SUS).

Keywords: Mental Health, Mental Health Services, Social Oppression, Personal Autonomy, Community Participation.

\section{O CAPS ad como Cenário de práticas do PET Saúde/Redes e o Teatro do Oprimido como Instrumento Clínico Político}

O Programa de Educação pelo Trabalho para a Saúde (PET), vinculado ao Programa Nacional de Reorientaçấo da Formaçáo Profissional em Saúde (Pró-Saúde), do Ministério da Saúde e do Ministério da Educação, desenvolvido por meio da parceria entre Universidades e as Secretarias Estaduais e Municipais de Saúde, objetiva a integração ensino-serviço-comunidade e a educação pelo trabalho (Farias-Santos \& Noro, 2017). No intuito de colaborar com a formação de graduandos para atuação no Sistema Único de Saúde (SUS), aptos à construção de práticas pertinentes a um modelo de atenção embasado por uma lógica psicossocial, que tem como norte a produção de cidadania, autonomia e inclusão social, situamos, no Estado do Espírito Santo, a experiência do PET Saúde/Redes de Atenção 2013-2015, em atenção à Portaria Conjunta no 9, de 24 de junho de 2013, da Secretaria de Gestáo do Trabalho e da Educação na Saúde e a Secretaria de Atenção à Saúde, do Ministério da Saúde. 
Este programa, realizado por meio de grupos de aprendizagem tutorial, no contexto das redes de atenção à saúde, objetivou contribuir no processo de implementação, desenvolvimento e qualificação da Rede de Atenção Psicossocial (RAPS), sobretudo, na atenção às pessoas que fazem uso abusivo de álcool e outras drogas. O PET Saúde/Redes de atençáo foi realizado por meio dos cursos de Terapia Ocupacional, Psicologia, Enfermagem, Medicina, Serviço Social, Farmácia e Odontologia, junto à Secretaria Municipal de Saúde e teve atuação em duas Unidades Básicas de Saúde (UBS) e em um Centro de Atenção Psicossocial - álcool e drogas (CAPS ad).

O modelo de atenção em saúde mental pautado pelo paradigma psicossocial, resultado do processo da Reforma Psiquiátrica Brasileira, busca, por meio da Clínica Ampliada (Campos, 1997), proporcionar, além do cuidado, um movimento de autonomia, inclusão social e cidadania. As formas de intervenção que repercutem sobre a realidade concreta do sujeito criam estratégias inclusivas, contam com a participação social, ampliam as possibilidades de trocas com a vida pública e de exercício da cidadania, assumem um caráter clínico e político.

Com a expansão de serviços, ações e programas pautados por uma lógica psicossocial, configurou-se a Rede de Atenção Psicossocial (RAPS), composta por Centros de Atenção Psicossocial (CAPS) com diferentes modalidades, Serviços Residenciais Terapêuticos (SRT), Consultório na Rua, serviços da Atenção Básica em Saúde, Serviços de Atenção em Urgência e Emergência, leitos psiquiátricos em Hospitais Gerais, entre outros (Brasil, 2011).

Pautando-se na preservação e fortalecimento dos laços sociais do usuário, cabe ao CAPS oferecer acolhimento e atenção às pessoas com sofrimento psíquico e às pessoas que fazem uso problemático de álcool e outras drogas. Núcleo de uma clínica inovadora, busca promover o protagonismo e a responsabilização do usuário em todo o processo do tratamento, propondo-se a produzir autonomia (Brasil, 2005).

O protagonismo e a autonomia remetem, inevitavelmente, às questóes de direitos de cidadania. Os Direitos de Cidadania se configuram em direitos civis (que garantem as liberdades individuais); direitos políticos (que permitem a participação no exercício do poder) e os direitos sociais (que permitem se desfrutar dos padrôes que prevalecem na sociedade). No caso específico das pessoas que fazem uso problemático de substâncias psicoativas (SPAs) em nossa sociedade, frequentemente, estas não são reconhecidas como cidadãs que devem ter seus direitos respeitados, mas são tidas como sujeitos marginais e dignos de exclusão social (Queiroz, 2001).

De modo geral, as condiçôes de vida das pessoas socialmente excluídas são pouco conhecidas até mesmo pelos profissionais de saúde. A exclusão social das pessoas nessas condições é, muitas vezes, justificada pelo preconceito do uso das substâncias, o que, segundo Andrade (2011), representa a expropriação total dos direitos, pois pode chegar à morte, sobretudo, pela classe social a qual pertencem.

Uma das formas de refletir sobre essa condição é o Teatro do Oprimido, método teatral sistematizado por Augusto Boal, elaborado no Brasil e em outros países da América Latina desde 1970. Em uma breve explicação aproximada, dado que Boal jamais elaborou uma definição exata de opressor, opressão ou oprimido, a opressão pode ser compreendida como um conjunto de sistemas organizados em formas de dominação e poder social, que podem ser culturais, sociais, políticos e históricos, em que indivíduos possam ser submetidos a essa força, ora como opressor, ora como oprimido, pois, ao 
mesmo tempo em que uma pessoa é oprimida, ela também pode ser opressora, dado o constante processo de mudança histórica e a possibilidade de conscientização desse movimento (Boal, 2019; Silva \& Abrantes, 2019).

O Teatro do Oprimido foi pensado como instrumento político e social, pois todo teatro é necessariamente político, pode funcionar como um agente de transformação social, sendo uma forma de conhecimento e potencializador da pró-ação e do exercício da cidadania (Boal, 2000, 2019). Tem como objetivo gerar a reflexão das ações individuais, de forma a produzir mudanças de atitudes opressoras na sociedade, possibilitando o protagonismo do espect-ator, como colocado por Boal, ao considerar que o espectador é sujeito, não apenas objeto e ator ao mesmo tempo, pois atua sobre o ator em cena. Assim, possibilita o despertar do indivíduo para o seu próprio processo de sentido, auxiliando-o a se conhecer como pessoa e a reconhecer as formas de opressão a que está submetido, bem como os possíveis caminhos para combatê-las, pois no Teatro do Oprimido não se encena fatos fictícios, mas personagens concretos da vida de quem conta sua história representando a realidade (Boal, 2002).

Desse modo, utilizamos como proposta de intervenção no âmbito do PET Saúde/Redes, junto ao CAPS ad, as técnicas do Teatro do Oprimido para promover o protagonismo dos participantes e possibilitar a identificação e o enfrentamento de suas necessidades e das diversas situaçôes de opressão que vivenciaram, bem como favorecer a interação e o estabelecimento de trocas entre usuários, familiares e profissionais, buscando fomentar o exercício da cidadania.

Neste artigo de relato de experiência do período de realização do PET Saúde Redes de Atenção junto ao CAPS ad, buscamos apresentar o trabalho realizado com as técnicas do Teatro do Oprimido e refletir sobre a sua potencialidade no contexto da Atenção Psicossocial.

\section{Metodologia}

Utilizamos a narração descritiva (Marcolino \& Mizukami, 2008) para apresentar o processo de realização das oficinas e, posteriormente, as situaçôes e intervençóes ocorridas nas oficinas e processos das mostras.

Durante quase todo o período de ocorrência do PET, um ano e meio, entre 2014 e 2015, foram realizadas oficinas terapêuticas, conduzidas por monitores acadêmicos do PET Saúde Redes e coordenado por uma aluna do curso de terapia ocupacional, que foi treinada na técnica do Teatro do Oprimido por meio de extensas leituras, palestras, cursos e workshop. Houve a participação variável de 12 a 22 usuários por oficina, que teve duração aproximada de duas horas.

Inicialmente, houve resistência por parte de alguns profissionais em garantir um espaço e um momento para a oficina. Então, foram utilizados os momentos em que os usuários se encontravam "livres", nos intervalos entre oficinas e grupos, para, posteriormente, conquistar um horário na agenda para a oficina e espaço físico também, pois, no início, os encontros ocorreram no refeitório, na quadra, no pátio, e posteriormente foram desenvolvidos no auditório do serviço.

Apresentamos aos usuários a teoria do Teatro do Oprimido e, ao identificarmos o interesse em trabalhar com essa ferramenta, passamos a nos reunir com eles para a escrita das peças e depois os ensaios, com a participação de usuários, trabalhadores do CAPS e 
acadêmicos do PET Saúde Redes. Os temas derivaram de suas próprias opressóes vivenciadas, ou que aconteceram com pessoas próximas. Cenas essas em que, de alguma maneira, emergia a figura do oprimido e do opressor.

Nesse processo de escrita, percebemos que o cotidiano dos usuários surgia simbolizado em personagens e cenas, com suas realidades e vivências, e no compartilhamento de histórias de opressão e de vida foi manifesto o desejo de teatralizálas.

O trabalho na oficina se configurou na divisão de 4 eixos básicos: desalienação corporal - foram utilizados diversos jogos teatrais do Teatro do Oprimido e técnicas de expressão corporal que favorecem a conscientização e desmecanização corporal e atitudinal; trabalhando conflitos - nesta etapa, os usuários foram instigados a falar de situaçôes de opressão que presenciaram, vivenciaram ou vivenciavam para que o grupo discutisse e aprofundasse reflexôes a esse respeito; teatralizando a opressáo - após as reflexões das situaçôes trazidas pelos usuários, o grupo elegeu algumas das situaçôes para serem teatralizadas e trabalhadas por meio da técnica do teatro do oprimido visando à transformação da realidade; e mostras de Teatro do Oprimido - nesta etapa, os usuários fizeram apresentações das peças que elaboraram na oficina.

Inicialmente, foram realizados os ensaios que resultaram na " 1 a mostra de Teatro do Oprimido". A partir dela, fortemente pautada no desejo manifesto pelos usuários, houve a proposta de continuar a técnica do Teatro do Oprimido e, desse modo, concretizaramse as $2^{\mathrm{a}}$ e $3^{\mathrm{a}}$ mostras, eventos para os quais foram convidados todos os usuários, seus amigos, familiares e demais membros das comunidades próximas, bem como os demais profissionais da instituição, acadêmicos e os professores tutores dos cursos de graduação participantes.

Desse modo, descrevemos como resultados os processos relativos às três mostras de Teatro do Oprimido: "Iniciando um caminho contra as opressôes" ( $1^{a}$ mostra), "Desvelando opressôes" (entre 2a e $3^{a}$ mostra) e "Se correr o bicho pega, se ficar o bicho come!" (3a mostra).

\section{Resultados: A Experiência do Teatro do Oprimido no CAPS ad}

\section{Iniciando um caminho contra as opressóes: a $1^{\text {a }}$ mostra do Teatro do Oprimido}

Na reunião de equipe do CAPS ad, após breve exposição sobre os trabalhos realizados nas oficinas, a primeira mostra teatral foi agendada e foi acordado que no mesmo horário não haveria outras oficinas ou atividades, para que todos os interessados (usuários e profissionais) pudessem participar. Apesar desse agendamento e ampla divulgação por meio de cartazes, houve a realizaçáo de atividades concomitantes ao evento.

A primeira mostra teve início com a declamação de uma poesia que foi rejeitada em ocasião anterior, de acordo com o usuário, por ter sido considerada "demasiado melancólica" pelo profissional responsável. Ao relatar sobre a rejeição, o usuário solicitou a leitura na abertura do evento. Assim, a "1a mostra de Teatro do Oprimido" foi aberta com a voz e protagonismo desse participante, que foi fortemente aplaudido pela plateia. 
Foram apresentados sete esquetes criados pelos usuários, com duração aproximada de cinco a sete minutos cada um, com as temáticas: "preconceito", "protagonismo na vida e no tratamento", "negligência familiar", "violação financeira relacionada ao uso de drogas", "relacionamento mãe-filho", "relacionamento homem-mulher e a interferência das drogas", "recaída em meio ao tratamento" e "conflitos entre os usuários".

A coordenadora, intermediando público e palco, pediu à plateia que elegesse três dos sete esquetes para serem reapresentados e debatidos por meio da técnica do Teatro do Oprimido. Os esquetes escolhidos foram: "Minhas escolhas dependem do outro", "E agora, quem paga a conta?", "É só umazinha!". Na reapresentação dos esquetes a plateia foi instigada a debater e a entrar em cena trazendo sugestóes e estratégias de enfrentamento às situaçóes de opressão.

Para o esquete "Minhas escolhas dependem do outro", uma usuária, a qual, conforme dito por um profissional, vivenciou sérios conflitos com sua mãe, culminando em sua saída da casa onde moravam, trouxe para cena a estratégia do diálogo entre mãe e filho como solução da opressão. Outra usuária, que em grupo terapêutico relatara um relacionamento conflituoso, com forte rejeição pelo filho, encenou uma mãe compreensiva e amorosa que buscou ouvir e acolher as necessidades do filho. Essa usuária relatou, no grupo terapêutico, seu movimento de construção de vínculo com o filho rejeitado. Uma convidada que estava na plateia, moradora de abrigo, estimulada por essa mesma cena, deliberou falar de seu relacionamento familiar conflituoso devido ao uso de substâncias psicoativas.

No esquete "E agora quem paga a conta?", alguns usuários desejaram entrar em cena no papel da mulher oprimida para debater com o marido opressor, trazendo diversas estratégias para romper com a opressão. Foram apresentadas propostas, como indicação de tratamento para o marido que faz uso abusivo do álcool, busca por um trabalho etc. Por meio do diálogo com o opressor, na tentativa de mudar a realidade, o divórcio surgiu como alternativa.

No último esquete escolhido, "É só umazinha!", os usuários apresentaram diferentes estratégias para evitar uma recaída, como rejeitar convites "perigosos" ao desviar de lugares onde a droga se faz presente e recomendar tratamento a amigos.

Os convidados externos também participaram reelaborando cenas, somando possibilidades e estratégias de combate às situações de opressão apresentadas. As trocas enriquecidas pela diversidade, o protagonismo, a voz e a visibilidade dados aos usuários e convidados, surgiram como recursos potencializadores possibilitados no evento.

Assim, ficou evidente o importante papel das técnicas do Teatro do Oprimido nessa primeira mostra, pois permitiu ao usuário um espaço para expressão de suas necessidades, de protagonismo, de visibilidade e de ampliação de trocas.

\section{Desvelando opressóes: entre a $2^{\mathrm{a}}$ e a $3^{\circ}$ mostra do Teatro do Oprimido}

$\mathrm{Na}$ semana seguinte ao primeiro evento, os usuários se organizaram para a próxima mostra de teatro, articulando-se para escreverem novas peças, outros trouxeram peças escritas e ainda perguntaram sobre a data de início da oficina anunciada no evento. Os trabalhadores que participaram da mostra também manifestaram forte apoio. Foram realizados dezesseis encontros que resultaram na organização da " 2 a mostra de Teatro do Oprimido", ocorrida no espaço do próprio serviço. 
Nas rodas de conversa, as histórias, de forma geral, tinham como temática o "preconceito" e a "exclusão social". Os usuários falaram de suas "vivências com a polícia", da "violência", dos "estigmas" que lhes eram atribuídos, relataram seus dramas, suas dores passadas e presentes.

Durante os jogos teatrais, observou-se o compartilhar das vivências e a expressão de sentimentos que apontavam necessidades. Quando reunidos em roda para falarem de como se sentiram em alguns jogos, rompia-se a fala marcada e temporizada percebida pela coordenadora em outros grupos ou oficinas, nos quais cada participante falava em sequência na roda, num tempo limitado, sendo seu olhar e sua fala geralmente direcionados ao profissional. Observamos a quebra dessa mecanicidade, com falas espontâneas e escuta por e para todos, num exercício de solidariedade e respeito mútuo.

O grupo ouvia cuidadosa e atentamente, identificando semelhanças, pois as histórias de uns, muitas vezes, eram comuns aos outros e novas histórias surgiam a partir dessa escuta. Foi possível perceber que, a cada encontro, eram tecidos tênues laços de solidariedade em meio às opressóes.

Durante os ensaios, os usuários criavam os personagens e diversas sugestóes eram experimentadas, cenários, açóes, falas, roupas, danças e músicas, numa relação potencializadora, em que todos eram importantes e tinham muito a oferecer, assumiram papéis e funções, contribuíram para a criação/encenação das peças e na organização da $2^{\text {a }}$ mostra de Teatro do Oprimido.

Em comparação com as oficinas que resultaram na $1^{\text {a }}$ mostra de Teatro do Oprimido, foi possível perceber nos encontros realizados maior protagonismo e empoderamento por parte dos usuários e maior participação de profissionais da equipe, tendo, inclusive, contado com o apoio direto da direção do serviço.

Numa das oficinas realizadas, a discussão sobre a palavra opressão foi definida como "imposição sofrida por alguém”, ou, "opressão é humilhação sofrida" e então foi significada por um usuário como: “Opressão é o CAPS ad!". Esse usuário relatou ter se sentido oprimido ao ser revistado pelos profissionais no momento de sua entrada no CAPS ad. Assim, como primeiro passo para produzir mudanças, os usuários começaram a identificar e refletir sobre suas opressōes, inclusive as vivenciadas na instituição. Contudo, alguns deles se mostraram inseguros em descrever e aprofundar situaçóes de opressão ocorridas no CAPS, temendo represálias no serviço.

Diante da necessidade de se debater as opressóes vivenciadas naquele espaço de cuidado, no intuito de garantir essa discussáo e minimizar o receio dos usuários, a coordenadora da oficina sugeriu ao grupo a apresentação da proposta à equipe: utilizar a técnica do Teatro do Oprimido, tanto por parte de usuários quanto de profissionais, para discutirem suas mútuas opressóes no serviço. Com a anuência dos usuários, a proposta foi levada aos profissionais que, em grande parte, apoiaram e se mostraram abertos a debater e a teatralizar as opressóes vivenciadas por eles e pelos usuários. É importante ressaltar que, ao retratar as atitudes opressoras dos profissionais, tomou-se o cuidado para não identificá-los e evitar constrangimentos, da mesma forma ocorreu com os usuários.

Sendo assim, a coordenadora retornou para os usuários que a proposta tinha sido aceita pela equipe e eles, então, ainda um pouco receosos, concordaram que a oficina se desse com foco nas opressões ocorridas no CAPS. Como resultado, por interesse dos usuários, foi delineado o debate dessas opressóes na $3^{\text {a }}$ mostra de Teatro do Oprimido. 


\section{“Se correr o bicho pega, se ficar o bicho come!": a $3^{\circ}$ mostra de Teatro do Oprimido}

Ocorreram doze encontros nos quais várias opressóes foram narradas, debatidas e as discussōes possibilitaram interessantes elaborações. Algumas narrativas, contudo, ainda foram proibidas por seus autores de serem teatralizadas devido ao temor de represálias. Histórias surgiam timidamente no discurso de quem não está certo de que é oprimido, afinal, para alguns usuários, atitudes opressoras de certos profissionais deveriam ser compreendidas e justificadas pelo "estresse e desgaste próprios do trabalho que realizavam", ou, o que alguns chamavam de opressão, outros chamavam de "necessária disciplina".

Em meio às discussôes, muitos daqueles que não se percebiam oprimidos, ou que procuravam justificativas para as atitudes opressoras, acabavam por se reconhecerem, sim, vítimas de opressão, e se interessavam em delinear formas de superá-las.

Usuários que não se expressavam verbalmente em outras oficinas passaram a sugerir formas de combate, indignados frente às opressóes apresentadas por eles ou pelo grupo. Anteriormente receosos com a repercussão de tal temática, agora se posicionavam unidos e fortalecidos, manifestando, inclusive, o desejo de que os profissionais, autores das opressóes apresentadas, estivessem presentes no dia da mostra de teatro. Desenvolvia-se, assim, a potência do grupo no combate à opressão.

Paralelamente à oficina, a coordenadora procurava, a cada reunião de equipe, agendar com os profissionais um dia para elaborarem suas cenas de opressão, o que foi feito em outro dia que não o de reunião e, assim, ao invés de elaborarem o trabalho com grande parte dos profissionais, contou-se com a participação de quatro, dos mais de vinte, em três encontros. Quanto às opressōes sofridas, alguns profissionais e a coordenadora da oficina perceberam que tais situaçóes teriam sido geradas por determinadas falhas do próprio serviço e não se configuravam verdadeiras opressóes, mas sim uma reação de defesa dos usuários ao serem oprimidos.

Diversas cenas de opressão foram encenadas e discutidas. Das histórias de opressão narradas pelos usuários, foram eleitas para serem teatralizadas: "A revista humilhante", que retratava a forma desrespeitosa com que alguns usuários eram revistados ao chegarem no serviço; "Autoridade máxima", referente ao autoritarismo de um profissional que, aos gritos, ameaçara expulsar do CAPS ad os usuários que estivessem "soltos" pelo espaço nos horários das oficinas; e "Deu a louca na doutora", cena em que uma usuária era submetida ao desrespeito e julgamento moral da profissional ao informar sobre sua suspeita de gravidez.

Como retrato da opressão vivenciada pelos profissionais, deliberou-se apresentar a cena em que o profissional, em meio a uma oficina, percebeu o desinteresse do usuário em participar e o convidou a sair da sala devido ao seu comportamento, julgado como inconveniente. Houve uma reaçáo considerada violenta por parte do usuário, direcionada ao profissional. Essa cena foi adaptada de forma que o profissional tentasse oferecer ao usuário outra proposta de atividade no lugar da oficina, sugerindo uma negociação de necessidades e não uma expulsão, como ocorreu. Marcaram-se mais dois encontros para o ensaio da cena, que ficou intitulada como "Se correr o bicho pega, se ficar o bicho come!". 
Cenas delineadas e ensaios realizados, foi agendada em reunião de equipe a $3^{a}$ mostra de Teatro do Oprimido, na qual todos os usuários, participantes das oficinas ou não, fizeram-se presentes e como espect-atores uniram esforços na luta contra a opressão.

Diante das cenas de opressão vivenciadas pelos usuários, foram fortemente elencadas como estratégias a busca pela figura do diretor do serviço, bem como a sugestão de procura pelos órgãos executivos e judiciários de defesa. Mas, sobressaiu, dentre as soluçóes e possibilidades de enfrentamento trazidas pela plateia, o exercício do protagonismo e da autonomia dos usuários que, unidos e esclarecidos em seus direitos, somavam suas forças e indignaçóes, exigindo respeito, qualidade de atendimento e justiça no espaço de cuidado.

Diante da cena, "Se correr o bicho pega, se ficar o bicho come", a plateia, sem a presença dos profissionais retratados, trouxe como solução a modificação da forma de abordagem do profissional que, com uma fala mais acolhedora e flexível, poderia ser melhor compreendido pelo usuário.

\section{Discussáo dos Resultados: o Teatro do Oprimido no CAPS ad como Potência para quê?}

Os esquetes apresentados foram escritos com base nas experiências reais das pessoas. Desse modo, conforme coloca Sanctum (2011), foi uma oportunidade de repensar o passado, debatê-lo e equacioná-lo no presente para assim planejar melhor açóes no futuro, já que, a partir da dificuldade social na resolução de conflitos, Boal criava jogos e técnicas a fim de encaminhar o debate com o objetivo de uma análise do presente para uma transformação da realidade. Para Boal (2002), todo ser humano é teatro em sua essência, dado que, de todos os animais, o ser humano é o único capaz de se observar enquanto age e, observando-se, é capaz de refletir sobre sua ação e tomar decisões, reinventar seu futuro analisando experiências passadas.

As vivências relatadas e teatralizadas tiveram como temas, de forma geral, o uso problemático de substâncias psicoativas relacionado às condições de estigmatização e preconceito, exclusão social, negligência familiar, violências, relacionamentos afetivos e familiares, abstinência e recaída, conflitos entre os usuários e opressão na instituição de cuidado, e ainda o protagonismo na vida e no tratamento.

Os participantes, ao serem ouvidos e acolhidos, eram potencializados, e, em meio à escrita, por vezes surgiam debates em que eram instigados a refletir sobre situaçóes de conflito e opressão vivenciadas por eles, e a pensar e repensar possibilidades de enfrentamento, saindo assim da passividade em que muitas vezes se encontravam.

Por meio da observação do movimento grupal, a coordenadora da oficina identificou o interesse e a iniciativa, bem como a escuta cada vez mais atenta e os apoios mútuos desenvolvidos pelos participantes.

Além disso, a expressão dos sofrimentos e opressôes pareciam apontar para singelas, mas importantes transformações possíveis. A voz do usuário ao manifestar a opressão no ambiente de cuidado demonstrava a mudança de lugar dos sujeitos, de pessoa "doente" e estigmatizada para o de pessoa com direitos de reivindicar atendimento mais humanizado e condizente com a lógica proposta para o serviço. 
Nos serviços de saúde, de modo geral, são observadas práticas, concepções e relações solidárias, mas também práticas, concepções e relações opressoras. Desde 2003, a Política Nacional de Humanização preconiza trocas solidárias entre gestores, trabalhadores e usuários do SUS, e a Reforma Psiquiátrica, com a perspectiva de desinstitucionalização, busca a produção de práticas que sejam mais condizentes com a cidadania das pessoas em situação de sofrimento psíquico e das pessoas em situação de uso problemático de SPAs.

Tomar o sujeito em processo de cuidado, com direito à cidadania, ao respeito e à singularidade é um dos desafios para o campo da saúde de modo geral. Há uma dimensão transformadora das práticas em saúde quando se considera o usuário como sujeito no processo e o que fragiliza as práticas é a permanência da visão biologicista e fragmentada (Schimith et al., 2011), que tem como consequência o estabelecimento de relação de poder, quando o usuário é visto apenas como o doente e, no caso do uso de álcool e outras drogas, como o "dependente químico".

Nessa experiência, percebemos que o próprio serviço se torna muitas vezes palco de opressóes que precisam ser ouvidas e discutidas para que não mais se reproduzam práticas distantes da Atenção Psicossocial.

As oficinas e os eventos se apresentaram como uma grande oportunidade de minimizar a lógica manicomial, portanto, opressora, na qual o usuário não tem voz. $\mathrm{E}$ compreendemos manicomial não apenas como um lugar, mas como uma prática social, cultural, política e ideológica (Merhy, 2007), que não produz protagonismo e inclusão social.

O espaço aberto aos profissionais para elaborarem, discutirem e elegerem suas cenas de opressão não foi tão bem utilizado como poderia, seja pela pouca adesão e interesse dos profissionais, seja pela restrição de horários e de encontros dados pela instituição. $\mathrm{O}$ fato é que a $3^{\text {a }}$ mostra do Teatro do Oprimido, ao expor determinadas feridas institucionais, abriu portas para discussões e debates, favorecendo, assim, o diálogo e o uso da tecnologia leve do cuidado, que, como classificou Merhy (2002), são tecnologias de relação, como a produção de vínculo e o acolhimento.

Como tecnologia leve, as oficinas terapêuticas, no contexto da Atenção Psicossocial e dos serviços substitutivos, passam a ser instrumentos não mais como recurso pedagógico e educativo no modelo clássico, ou como forma de ocupação do tempo ocioso na perspectiva institucional, mas seu uso é em prol da criação de novas relações sociais, restabelecidas por meio do resgate da linguagem e da cidadania das pessoas. Nesse sentido, "[...] a dimensão essencial das oficinas refere-se à articulação da dimensão sociopolítica com a dimensão da subjetividade [...]" (Costa \& Figueiredo, 2008, p. 55), e, portanto, um instrumento clínico-político em nossa experiência.

A utilização da técnica do Teatro do Oprimido no contexto da Atenção Psicossocial produz práticas potencializadoras para o cuidado das pessoas que fazem uso problemático de SPAs, pelas possibilidades de expressividade, emancipaçáo, protagonismo, recriação de relações, enfrentamento de estigmas, exercício dos direitos de cidadania, entre outros aspectos, que configuram uma importante estratégia de Reabilitação Psicossocial (Silva et al., 2011; Santos et al., 2016).

Essa experiência proporcionada pelo PET Saúde/Redes de Atenção apresentou condição de estimular transformação na postura dos usuários, dos graduandos e dos 
trabalhadores de saúde mental, que algumas vezes verbalizaram a importância de nossa atuação no serviço.

Atualmente, o processo de Reforma Psiquiátrica Brasileira está sob ameaças devido a distorções nas diretrizes pelas recentes resoluções e portarias, aprovadas em 2018, na contramão do que vinha sendo proposto pela Política Nacional de Saúde Mental, Álcool e Outras Drogas, com a inserção do Hospital Psiquiátrico e de Comunidades Terapêuticas no modelo de atenção psicossocial, a partir de interesses fundamentalistas e neoliberais (Sousa \& Jorge, 2019), o que aponta para importantes retrocessos que vão na contramão de políticas globais, com bons indicadores epidemiológicos de saúde mental, e tornam claras intençóes de um projeto político que vai na contramão da garantia dos direitos humanos (Lussi et al., 2019).

Diante desse cenário, é importante afirmar a potência do uso do Teatro do Oprimido no CAPS, pois esses são serviços que propiciam a produção de práticas para o enfrentamento aos movimentos de exclusão social a partir, mais do que antes, do questionamento das estruturas cristalizadas do poder e do saber que promovem a opressão.

A fim de que a atividade não se torne um momento de culpabilização ou vitimização e queixas, para o uso adequado do Teatro do Oprimido como potente recurso, é preciso, necessariamente, capacitação e afinidade com esse instrumento artístico e político. Nesse sentido, inferimos que a atuação da coordenadora da oficina, graduanda naquele momento em terapia ocupacional, facilitou e apresentou importante contribuição, considerando ser essa uma formação ampla que articula conhecimentos do campo da saúde e das ciências sociais para a promoção do protagonismo, da participaçáo social e da conscientização das açôes cotidianas possíveis na perspectiva da desinstitucionalização e da atenção psicossocial.

\section{Consideraçóes Finais}

A atuação com o Teatro do Oprimido no CAPS-ad se configurou como um trabalho de caráter clínico e político, com atuação sobre a realidade concreta dos protagonistas de suas próprias histórias encenadas. Com a participação ativa dos usuários, houve seu envolvimento espontâneo desde a elaboração até a execução dos eventos e nas oficinas, o estímulo à corresponsabilização em seu próprio tratamento, bem como na vida, em busca de estratégias que atuem sobre as problemáticas apresentadas por eles. Assim, as técnicas do Teatro do Oprimido, que tem como veículo a arte, apresentam potência para permitir que a voz das pessoas em situação de estigmatização possam ser ouvidas e também para fomentar mais consciência das opressóes e reavaliar posturas e modos de ação, para assim transformar a realidade.

Diante dessa experiência, cabe, como questão para estudos futuros, compreender a visão dos usuários de CAPS ad sobre o impacto em seu cotidiano a partir de sua participação em atividades dessa natureza.

Para a formação em saúde, no campo da saúde mental especificamente, ainda se faz presente como desafio o alinhamento técnico e ético para o cuidado na direção do paradigma psicossocial. Nesse sentido, afirmamos a riqueza dessa experiência por meio 
do PET Saúde/Redes, no sentido de provocar reflexôes e críticas que possam vir a qualificar ações em prol da Atenção Psicossocial no âmbito do SUS.

\section{Referências}

Andrade, T. M. (2011). Reflexōes sobre políticas de drogas no Brasil. Ciencia \& Saude Coletiva, 16(12), 4665-4674. http://dx.doi.org/10.1590/S1413-81232011001300015.

Boal, A. (2000). Jogos para atores e não-atores. Rio de Janeiro: Editora Civilização Brasileira.

Boal, A. (2002). O arco-iris do desejo: método Boal de teatro e terapia. Rio de Janeiro: Civilização Brasileira.

Boal, A. (2019). O teatro do oprimido e outras poéticas politicas. São Paulo: Editora 34.

Brasil. (2005). Documento apresentado à Conferência Regional de Reforma dos Serviços de Saúde Mental: 15 anos depois de Caracas. Brasília: Ministério da Saúde.

Brasil. (2011). Portaria n 3.088, de 23 de dezembro de 2011. Institui a Rede de Atenção Psicossocial para pessoas com sofrimento ou transtorno mental e com necessidades decorrentes do uso de crack, álcool e outras drogas, no âmbito do Sistema Único de Saúde (SUS). Diário Oficial [da] República Federativa do Brasil, Brasília, seção 1.

Campos, G. W. (1997). A clinica do sujeito: por uma clinica reformulada e ampliada. Campinas: Mimeo.

Costa, C. M., \& Figueiredo, A. C. (2008). Oficinas terapêuticas em saúde mental - sujeito, produção e cidadania (Coleçôes IPUB). Rio de Janeiro: Contra Capa Livraria.

Farias-Santos, B. C. S., \& Noro, L. R. A. (2017). PET-Saúde como indutor da formação profissional para o Sistema Único de Saúde. Ciencia \& Saude Coletiva, 22(3), 997-1004. http://dx.doi.org/10.1590/1413-81232017223.15822016.

Lussi, I. A. O., Ferigato, S. H., Gozzi, A. P. N. F., Fernandes, A. D. S. A., Morato, G. G., Cid, M. F. B., Furlan, P. G., Marcolino, T. Q., \& Matsukura, T. S. (2019). Saúde mental em pauta: afirmaçáo do cuidado em liberdade e resistência aos retrocessos. Cadernos Brasileiros de Terapia Ocupacional, 27(1), 1-3. http://dx.doi.org/10.4322/2526-8910.ctoed2701.

Marcolino, T. Q., \& Mizukami, M. G. N. (2008). Narrativas, processos reflexivos e prática profissional: apontamentos para pesquisa e formação. Interface Com. Educ, 12(26), 541-547.

Merhy, E. E. (2002). Saúde: a cartografia do trabalho vivo. São Paulo: Hucitec.

Merhy, E. E. (2007). Os CAPS e seus trabalhadores no olho do furacấo antimanicomial. alegria e alivio como dispositivos analisadores. In E. E. Merhy \& H. Amaral (Orgs.), A reforma psiquiátrica no cotidiano II (pp. 55-66). São Paulo: Hucitec.

Queiroz, I. S. (2001). Os programas de reduçâo de danos como espaços de exercício da cidadania dos usuários de drogas. Psicologia, 21(4), 2-15. http://dx.doi.org/10.1590/S1414-98932001000400002.

Sanctum, F. (2011). Estética do oprimido de Augusto Boal: uma odisséia pelos sentidos (Dissertação de mestrado). Universidade Federal Fluminense, Rio de Janeiro.

Santos, E. S., Joca, E. C., \& Souza, A. M. A. (2016). Teatro do oprimido em saúde mental: participação social com arte. Interface: Comunicacao, Saude, Educacao, 20(58), 637-647. http://dx.doi.org/10.1590/1807-57622015.0469.

Schimith, M. D., Simon, B. S., Brêtas, A. C. P., \& Budó, M. L. D. (2011). Relaçóes entre profissionais de saúde e usuários durante as práticas em saúde. Trabalho, Educação e Saúde, 9(3), 479-503. http://dx.doi.org/10.1590/S1981-77462011000300008.

Silva, A. C. S., \& Abrantes, D. S. S. (2019). Da invisibilidade ao protagonismo: pessoas em situação de rua. Revista Tempo Amazônico, 6(2), 180-200.

Silva, J.J.S., Silva, P.M.C., Azevedo, E.B., Ferreira Filha., M.O., \& Cordeiro, R.C. (2011). Desvelando os caminhos do teatro do oprimido como estratégia de reabilitação psicossocial. Revista de Pesquisa: Cuidado é Fundamental Online, 3(Supl.), 164-175. 
Sousa, F. S. P., \& Jorge, M. S. B. (2019). O retorno da centralidade do hospital psiquiátrico: retrocessos recentes na política de saúde mental. Trabalho, Educação e Saúde, 17(1), e0017201.

http://dx.doi.org/10.1590/1981-7746-sol00172.

\section{Contribuiçáo dos Autores}

Adriana Leấo e Suzana Rodrigues Renó trabalharam juntas na concepção do texto. Suzana Rodrigues Renó foi monitora do Programa de Educação pelo Trabalho para a Saúde (PET Redes) e atuou como coordenadora da oficina, orientada por Adriana Leáo. Todos os autores aprovaram a versão final do texto.

\section{Fonte de Financiamento}

Financiamento de açôes de educação em saúde por meio da concessão de bolsas - DEGES/SGTES/MS (2013-2015).

\section{Autor para correspondência}

Adriana Leão

e-mail: drileao@gmail.com

\section{Editora de seçáa}

Isabela Aparecida de Oliveira Lussi 